\title{
Human RECQ helicases: roles in cancer, aging, and inherited disease
}

This article was published in the following Dove Press journal:

Advances in Genomics and Genetics

29 December 2014

Number of times this article has been viewed

Julia M Sidorova ${ }^{1, *}$

Raymond J Monnat Jr ${ }^{1,2, *}$

'Department of Pathology,

${ }^{2}$ Department of Genome Sciences, University of Washington, Seattle,

WA, USA

*The authors contributed equally to this review
Correspondence: Raymond J Monnat Jr Department of Pathology, University of Washington, Box 357470 ,

Seattle, WA, USA

$\mathrm{Tel}+\mathrm{I} 2066167392$

Fax + I 2065433967

Email monnat@u.washington.edu
Abstract: DNA helicases use the energy of ATP hydrolysis to disrupt DNA base pairing and displace proteins from DNA in order to facilitate replication, recombination, transcription, and repair. This article focuses on the human RECQ helicases, five DNA-dependent helicases that play key roles in cellular physiology and disease. Loss of function of three RECQ helicases causes the cancer predisposition syndromes Bloom syndrome, Werner syndrome, and Rothmund-Thomson and related syndromes. We summarize recent work on these syndromes and proteins and discuss disease pathogenesis in light of RECQ helicase biochemical activities and in vivo functions.

Keywords: ATP-dependent DNA helicase, Bloom syndrome, Werner syndrome, RothmundThomson syndrome, DNA replication, DNA repair, genetic instability, cancer predisposition syndrome

\section{Introduction}

Helicase proteins are ubiquitous enzymes that use the energy of ATP hydrolysis to disrupt DNA or RNA base pairing and promote the unwinding of double-stranded DNA (dsDNA) or RNA duplexes or DNA:RNA hybrid molecules. Helicases can also displace or translocate proteins on DNA and RNA. ${ }^{1-4}$ This article focuses on five members of the human RECQ helicase family, and our understanding of their roles in cellular DNA metabolism and disease. We highlight important recent advances and refer interested readers to other recent reviews that cover these and additional aspects of this rapidly evolving area of human biomedical research.

\section{The RECQ helicase deficiency syndromes}

The RECQ helicase deficiency syndromes Bloom syndrome (BS), Werner syndrome (WS), and Rothmund-Thomson (RTS) and related syndromes are rare $(\leq 1 / 50,000$ live births), autosomal-recessive Mendelian diseases that share an elevated risk of cancer together with additional features including genetic instability and developmental and disease-specific acquired features. We review key features of the deficiency syndromes to start as these provide a useful focus for thinking about RECQ function and the consequences of loss.

BS is characterized by growth retardation, congenital short stature, and a characteristic sun-sensitive "butterfly" rash across the bridge of the nose and cheeks that may extend to involve the hands and forearms. ${ }^{5,6}$ Many BS patients display both cellular and humoral immune deficits together with an elevated risk of otitis media and pneumonia, an elevated risk of diabetes mellitus, and often reduced fertility. ${ }^{7}$ Cancer is the most troubling acquired disease risk and leading cause of death. Cancer risk in 
$\mathrm{BS}$ is unusual in that it encompasses many different tumor types, including common adult epithelial tumors (eg, colon, breast, and lung cancer), leukemias, lymphomas, sarcomas, and a range of embryonal tumors (Wilms' tumor, medulloblastoma, and retinoblastoma). ${ }^{8}$

WS alone among the RECQ helicase syndromes has features strongly suggestive of premature aging. Key clinical findings include short stature, early graying and loss of hair, bilateral subcapsular cataracts, and scleroderma-like skin changes. $^{9-13}$ The earliest and most consistent changes are graying and loss of hair beginning with the scalp and eyebrows in the second decade of life, followed by cataract development. The short stature of WS patients is primary - a failure to undergo an adolescent or pubertal growth spurt - rather than the result of an endocrine disturbance. Subcutaneous connective tissue atrophy and dermal fibrosis give skin a "tight, white, and shiny" appearance that with time leads to a progressive sharpening of facial features, foot and ankle deformities with ulceration, and soft tissue calcification. WS patients are at increased risk of atherosclerosis, myocardial infarction and stroke, osteoporosis, and diabetes mellitus. Fertility is reduced in males and females. ${ }^{9-12}$ The central nervous system is typically spared, and WS patients are not at elevated risk of Alzheimer or other types of age-associated dementia apart from those associated with vascular disease.

In contrast to BS, WS confers an elevated risk of only selected types of cancer. ${ }^{14-17}$ The most frequently observed neoplasms are soft tissue sarcomas, follicular thyroid carcinoma, meningioma, acral lentiginous malignant melanoma, malignant or preneoplastic hematologic disease (chiefly leukemias), and osteosarcoma. Cancer and premature cardiovascular disease are the leading causes of death in WS patients. ${ }^{18-20}$
RTS was first described as a familial occurrence of unusual skin changes together with bilateral juvenile cataracts. ${ }^{21-24} \mathrm{~A}$ characteristic sun-sensitive rash with redness, swelling, and blistering typically appears within the first year of life and may extend to involve the buttocks and extremities while sparing the chest, back, and abdomen. The rash may evolve over time to include variable pigmentation, telangiectasias, and focal atrophy. Hair, eyelashes, and eyebrows are often sparse or absent. Congenital short stature is common, though less severe than in BS. Bone and tooth abnormalities include dysplastic, malformed, or absent bones, often in the hand or thumbs; delayed bone formation or bone density loss; and malformed, missing, or extra teeth. The cataracts originally noted by Rothmund have been documented in only a minority of contemporary RTS patients. ${ }^{25,26}$ Cancer risk is elevated, though largely limited to osteosarcoma. ${ }^{25,27,28}$ Immunologic function appears to be intact, but fertility may be reduced. Life expectancy in the absence of cancer appears to be normal. ${ }^{25,26}$ Two additional syndromes associated with RECQL4 mutations are RAPADILINO and Baller-Gerold (BGS) syndromes. RAPADILINO syndrome patients have joint dislocations and patellar hypoplasia or aplasia, but lack the skin changes seen in RTS patients. BGS patients have craniosynostosis with radial aplasia in addition to skin changes reminiscent of RTS. ${ }^{29,30}$

\section{RECQ genes, deleterious mutations, and genomic variants}

The genes causally linked to BS, WS, and RTS are members of the human RECQ helicase gene family (Figure 1)., ${ }^{4,31} B L M$ was cloned in 1995 by making clever use of the mitotic recombination phenotype of $\mathrm{BS}$ cells ${ }^{32}$ and led to naming of the family after the helicase domain shared with the

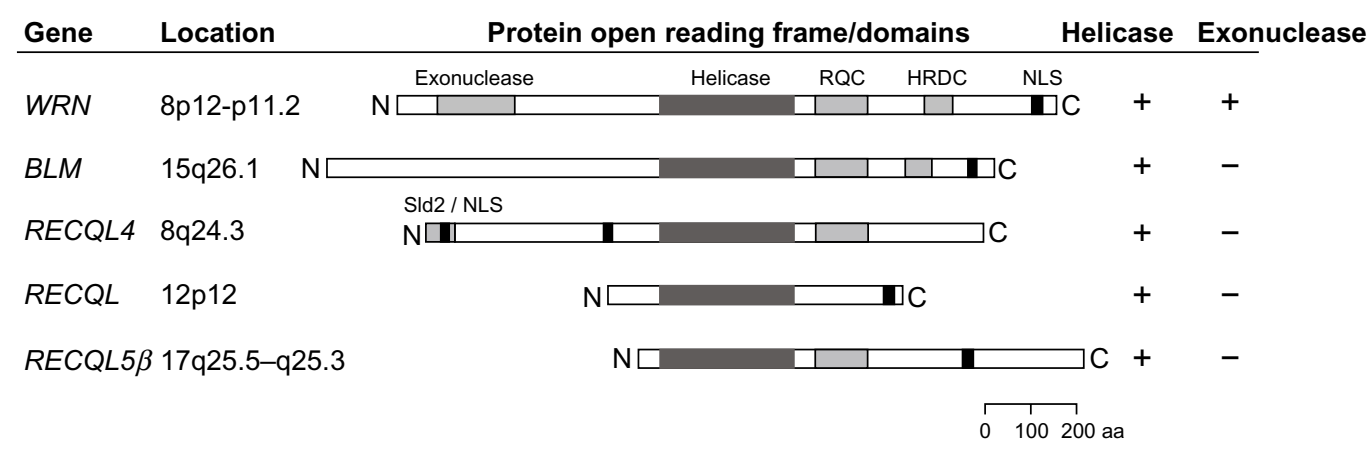

Figure I Human RECQ helicase genes and proteins.

Notes: The five human RECQ helicase proteins are shown as boxes (center). Gene symbols (gene) and chromosomal locations (location) are indicated to the left of each protein open-reading frame, which is depicted as a box with domains indicated by boxed segments. All five proteins share a central, conserved RECQ helicase domain that encodes a $3^{\prime}-5^{\prime}$ helicase activity (helicase). Three family members contain RECQ Consensus (RQC) domains, and two contain a Helicase and RNase D C-terminal (HRDC) domain. Nuclear localization signals (NLS) are depicted as short filled boxes. The $3^{\prime}-5^{\prime}$ exonuclease domain (exonuclease) is unique to WRN, whereas the SId2 homology domain is found only in RECQL4. 
Escherichia coli RecQ protein. Positional cloning of the $W R N$ gene in 1996 was guided by prior linkage analyses ${ }^{33}$ and confirmed earlier speculation that the $W R N$ gene might be a helicase. ${ }^{34}$ RECQL4 and RECQL5 cloning were based on sequence homology. ${ }^{35,36}$ The remaining family member, $R E C Q L$, was identified independently by two groups by virtue of encoding a potent ATPase and helicase activity in human cell extracts. ${ }^{37,38}$ RECQL and RECQL5 have not been linked to human disease though, and as we outline below, there is abundant evidence that heritable loss of function of either has the potential to lead to disease. ${ }^{39-43}$

$B L M$ mutations ascertained in BS patients invariably lead to a loss of helicase function, ${ }^{44}$ though do not in all cases eliminate mutant protein expression. In contrast, in WS patients mutations in WRN lead to loss of the WRN protein and both two associated catalytic activities ${ }^{45,46}$ : it appears the loss of both WRN catalytic activities are required to generate WS cellular and clinical phenotypes. ${ }^{47,48}$ Recently reported missense mutations affecting the $W R N$ helicase domain ${ }^{49}$ have a high likelihood of destabilizing the mutant protein, as did a previously reported pair of homozygous missense mutations in the exonuclease domain. ${ }^{18}$ A surprisingly large number of patients referred with suspected WS lack WRN mutations. ${ }^{18,49}$ Among the subset that fulfill the diagnostic criteria for WS may be individuals with $W R N$ gene silencing, with mutations in proteins required for WRN function, or with novel progeroid syndromes. These patients are prime candidates for targeted exome sequencing.

RECQL4 mutations have been linked to RTS, RAPADILINO, and BGS syndromes. RTS is genetically heterogeneous, with only a portion of clinically ascertained patients having RECQL4 mutations. ${ }^{26,27,29,30} \mathrm{BGS}$ is also genetically heterogeneous, with subsets of patients having FGFR 2 or TWIST mutations. ${ }^{26}$ Two other features of clinically ascertained RECQL4 mutations are worth noting. First, an unusually high proportion of recurrent RECQL4 mutations disrupt splicing. This is explained by the genomic structure of the human RECQL4 gene. ${ }^{50}$ Second, disease-associated mutations invariably spare the N-terminal portion of the RECQL4 protein. This region shares homology with the yeast replication protein Sld2, which suggests that the Sld2 homology domain of RECQL4 may be essential for DNA replication. ${ }^{51,52}$ All the human $R E C Q$ genes have population polymorphic variants of unknown significance in addition to the clearly pathogenic mutations. One WRN polymorphic variant, R834C, has been shown to affect WRN helicase activity, ${ }^{53}$ though it does not clearly confer a clinical phenotype resembling WS (A Kamath and L Loeb, personal communication, September 12, 2014).

\section{RECQ helicase biochemical activities}

The enzymatic activities and substrate preferences of the human RECQ helicases have been studied in detail ${ }^{4,31,54-61}$ and have been summarized in Table 1. All the RECQ helicases unwind DNA duplexes with moderate processivity by translocating along one of the strands in $3^{\prime}-5^{\prime}$ direction while hydrolyzing ATP, and all possess good DNA strand annealing activity. The application of technologies such as single-molecule fluorescence resonance energy transfer and magnetic tweezers ${ }^{62}$ have revealed that BLM unwinds a forked partial duplex DNA in repetitive spurts, with a probability of strand reannealing that increases as a function of the length of unwound DNA. ${ }^{63}$ Singlestranded DNA binding protein, replication protein A (RPA), etc, stimulates processivity and can shorten the pause between reannealing and the next unwinding cycle. These observations suggest an unwinding model in which BLM switches to the opposite strand of its DNA substrate at the end of the unwinding spurt and translocates by backtracking in a $3^{\prime}-5^{\prime}$ direction while reannealing single-stranded DNA (ssDNA).

This cycle of unwinding, strand switching, and backtracking with reannealing has been extended by analyses of the activity of two Arabidopsis thaliana RECQ helicases,

Table I Enzymatic activities of human RECQ helicases

\begin{tabular}{|c|c|c|c|c|c|c|c|c|c|}
\hline \multirow{2}{*}{$\begin{array}{l}\text { RECQ } \\
\text { helicase }\end{array}$} & \multicolumn{4}{|c|}{ Substrate specificity of unwinding } & \multicolumn{5}{|c|}{ Model physiologic substrate activities } \\
\hline & $\begin{array}{l}\text { Forked } \\
\text { duplex }\end{array}$ & D-loop & $\begin{array}{l}\text { 4-way } \\
\text { junction }\end{array}$ & G-quadruplex & $\begin{array}{l}\text { Branch } \\
\text { migration }\end{array}$ & $\begin{array}{l}\text { Fork } \\
\text { regression }\end{array}$ & $\begin{array}{l}\text { Holliday } \\
\text { junction } \\
\text { dissolution }\end{array}$ & $\begin{array}{l}\text { DNA-protein } \\
\text { complex } \\
\text { disruption }\end{array}$ & $\begin{array}{l}\text { Single strand } \\
\text { annealing }\end{array}$ \\
\hline WRN & + & + & + & + & $+^{55}$ & + & - & - & + \\
\hline BLM & + & + & + & + & $++^{55}$ & + & + & RAD5I-DNA & + \\
\hline $\mathrm{RECQL}^{59}$ & + & + & + & -55 & $+^{55}$ & - & - & $++^{164}$ & + \\
\hline RECQL4 & + & $t^{\mathrm{a}}$ & - & - & - & & - & & + \\
\hline RECQL5 58 & + & - & - & - & $+^{55}$ & + & - & RAD5I-DNA & + \\
\hline
\end{tabular}

Notes: Data summarized from Singleton et al, ${ }^{\prime}$ Vindigni et $\mathrm{al}^{2}{ }^{2}$ Brosh et $\mathrm{al}^{3}$ and Croteau et al ${ }^{4}$ with new results indicated by references adjacent to + or - symbols within the Table. Empty cells within the Table represent an absence of data. ${ }^{a}$ Activity in the presence of excess single-stranded DNA. 
AtRECQ2 (a WRN homologue) and AtRECQ3 (which may be analogous to human RECQL5), on hairpin substrates. AtRECQ2 activity favors unwinding, whereas AtRECQ3 favors reannealing. ${ }^{64}$ These dynamic activities help inform thinking about RECQ helicase actions on biological substrates: cycles of unwinding and reannealing may enable or antagonize specific DNA metabolic processes, while providing opportunities to further regulate RECQ function and the DNA metabolic pathways in which they function.

The human RECQ helicases display different activities on in vitro and model physiologic substrates (Table 1). For example, only BLM and WRN can unwind non-B-form DNAs such as G-quadruplexes (G4), which may correlate with these two RECQ helicases possessing helicase and RNase D C-terminal domains. Likely in vivo genomic targets for this G4-specific activity are G-rich DNAs such as telomeres, ribosomal RNA genes, and G-rich simple sequence repeats and G4 DNA elements in transcribed genes. ${ }^{65-68}$ WRN, BLM, and RECQL can all branch-migrate four-way/ Holliday junctions (HJs); however, only BLM can dissolve these structures in concert with topoisomerase III $\alpha$, RMI1, and RMI2 (the RMI's are both RECQ-Mediated Genome Instability proteins). HJ resolution and dissolution are important in homology-dependent recombination (HR) and DNA replication as we discuss below. WRN can unwind DNA:RNA duplexes, as well as substrates in which one strand has mixed RNA-DNA content similar to that observed in Okazaki fragments. ${ }^{69} \mathrm{WRN}$ alone among the human RECQ helicases contains a $3^{\prime}-5^{\prime}$ exonuclease activity, which is active on many of the same substrates that can be unwound by WRN helicase activity. ${ }^{70-73}$ The WRN exonuclease can degrade recessed 3' ends in dsDNA and initiate DNA degradation from nicks or gaps in dsDNA. ${ }^{74}$ Finally, the WRN exonuclease can proofread by excising mismatched $3^{\prime}$ nucleotides in primer/ template substrates. ${ }^{75}$

All the human RECQ helicases interact physically and functionally with other DNA metabolic proteins, ${ }^{4,57,60}$ and novel interactions continue to be discovered. We touch upon some of the most prominent interactions below when we discuss specific DNA metabolic processes. The RECQ proteins also interact with one another. Examples include the physical and functional interaction of WRN and BLM, with BLM inhibiting the exonuclease activity of WRN, ${ }^{76}$ and the functional cooperativity of RECQL and RECQL4 in replication. ${ }^{43}$ More recently, RECQL4 has been shown to associate with BLM in vivo and in vitro and stimulate BLM helicase activity on forked DNA substrates. ${ }^{77}$ Similar results have been demonstrated for RECQL5 and WRN. ${ }^{78}$

\section{RECQ helicase roles in nucleic acid metabolism}

Individual RECQ helicases share common or overlapping roles and may display additional distinct or unique roles in different DNA metabolic processes. We summarize some of the better characterized of these roles below.

\section{DNA double-strand break repair}

DNA double-strand breaks (DSBs) are potentially lethal lesions that can be generated by exogenous DNA damage (eg, $\mathrm{X}$ rays, radiomimetic chemicals, laser-induced strand breaks) as well as by endogenous processes such as immunoglobulin class switching and DNA replication. Cell-based assays have implicated all five RECQs in DSB repair by nonhomologous DNA end joining (NHEJ) or HR. The mechanistic choice between these two options has been a recent focus of intense research, as pathway choice together with activity and fidelity can have a profound impact on genomic stability and cell viability. $^{79}$

A key determinant of DSB repair pathway choice is the extent of $5^{\prime}$ DNA end resection to generate recombinogenic 3 '-extended ssDNA overhangs. End resection and pathway choice are regulated by the regulatory and enzymatic interplay of $\sim 40$ proteins, with prominent regulatory roles for BRCA1, 53BP1, POT1, and RIF $1{ }^{80}$ BLM and WRN can, in conjunction with the multifunctional endonuclease DNA2 or the exonuclease EXO1, promote extensive resection of DSBs ${ }^{81-83}$ after initial short resection initiated by CtIP and the MRE11/ RAD50/NBS1 complex. The specific contribution of these seemingly redundant resection activities is likely to be dictated by the extent of damage, DNA end chemistry, cell cycle phase, and chromatin context. ${ }^{84-86} \mathrm{HR}$-promoting proteins, eg, WRN and BLM in association with the MRE11/RAD50/ NBS1 complex and HR factors BRCA1, RAD51, and EXO1 may compete with NHEJ-promoting proteins such as WRN together with $\mathrm{Ku} 70 / 80$, DNA-PKc, and LigaseIV/XRCC4 to regulate resection. One potential difference between WRN, BLM, and EXO1 is the requirement for CtIP to join long resected ends in BLM-depleted cells. ${ }^{87}$ Other contributions of RECQL and WRN to NHEJ are summarized in two recent comprehensive reviews. ${ }^{4,88}$ RECQL4 also appears to play a role in NHEJ in conjunction with $\mathrm{Ku} 70 / 80$, by a mechanism yet to be fully elucidated. ${ }^{89}$ While the recruitment of RECQL4 to laser-induced DNA breaks has been documented, ${ }^{90}$ it is unclear whether this localization has functional significance independent of WRN or BLM.

Both WRN and BLM also play an important role in the late, postsynaptic phase of HR when recombinant DNA 
duplexes are topologically disentangled and segregated. Likely substrates include D-loop (three-stranded), as well as fourstranded HJ-type recombination products that can be separated by endonuclease cleavage and unwinding or dissolved by topoisomerase-mediated unlinking. The roles of BLM in promoting and suppressing D-loop formation are well understood, as is the unique ability of the BLM 'dissolvasome' consisting of BLM/topoisomerase III $\forall /$ RMI1/RMI2 to suppress crossover products from $\mathrm{HJ}$ or hemi-catenane substrates. ${ }^{91-93}$ The role of WRN in HJ resolution or D-loop unwinding is well-supported by molecular data, ${ }^{48,94}$ which reflects the strong bias in favor of non-crossover product generation to prevent potentially deleterious genome instability or rearrangement. ${ }^{92}$ Finally, RECQL5 may antagonize HR by disrupting RAD51/ ssDNA filament formation to suppress D-loop generation in a manner similar to BLM. ${ }^{95,96}$

The recombination activities of RECQ helicases may have an important subsidiary role in mitotic division by removing physical links between sister chromatids at the end of S-phase (reviewed in Manthei and $\mathrm{Keck}^{93}$ ). The likely substrates here are catenanes or hemi-catenanes left by fork stall/restart events or at replication termini. Unresolved physical links between sister chromatids can be seen as ultra-fine bridges between chromatids at mitosis. They are prevalent in centromeric and telomeric DNA, and BLM in conjunction with Fanconi Anemia pathway proteins appear to play an important role in ultra-fine bridge resolution prior to mitosis. ${ }^{97,98}$ Ultra-fine bridges are one example of an apparently unique role for BLM. ${ }^{93} \mathrm{BLM}^{99}$ and RECQL5 ${ }^{100}$ together with topoisomerase II $\forall$ may also play a role in chromatid decatenation prior to mitosis.

\section{Additional repair roles}

RECQ helicases appear to function in several other DNA repair pathways. ${ }^{4}$ For example, WRN and RECQL4 participate in base excision repair by virtue of physical and/ or functional interactions with APE1 endonuclease, DNA polymerase $\beta$, or in the case of WRN with NEIL1, a DNA glycosylase. ${ }^{4}$ RECQL5 and RECQL support cellular resistance to oxidative damage ${ }^{101,102}$ as does WRN. RECQL5 may play an additional role in ssDNA break repair and is the only RECQ protein recruited to laser-induced single-strand breaks in vivo. ${ }^{102}$

\section{Global roles in DNA replication}

All five of the human RECQ helicase proteins play important roles in DNA replication. RECQ helicases associate with key replication or replication accessory proteins such as
DNA polymerases, proliferating cell nuclear antigen, flap endonuclease 1, and RPA. RECQL4, and to a lesser extent RECQL, both bind replication origins and contribute to replication initiation. ${ }^{43,103}$ RECQL4 is found associated with the replication initiation complex via interaction with MCM10 and is required for replication initiation complex assembly (reviewed in Masai ${ }^{55}$ ). RECQL4's unique Sld2-like N-terminal DNA-binding domain, ${ }^{104}$ may be involved in this specialized function. Given the central role for RECQL4 in DNA replication initiation, it is not surprising that RECQL4-deficient cells have a proliferation defect, elevated DNA damage signaling, and a higher proportion of senescent cells in culture as well as in mouse models reflecting the consequences of disrupted or incomplete DNA replication. ${ }^{43,105-107}$ Several mouse models of Recql4 deficiency have begun to give information on the lineage-specific consequences of loss of Recql4 function, most notably in maintenance of hematopoiesis. One intriguing aspect of this lineage-specific role is that it does not require the Recql4 helicase activity. ${ }^{107,108}$

The availability to stretch, capture, and visualize individual replicating DNA molecules, a methodology often referred to as DNA fiber stretch or DNA 'combing', has enabled the quantitative analysis of replication dynamics in vivo. DNA fiber data have identified roles for BLM, ${ }^{109,110}$ WRN, ${ }^{110,111}$ and RECQL ${ }^{43,112}$ in replication fork rate maintenance in human cells in culture. Interestingly, the depletion of RECQL5 in WRN-deficient cells severely depresses replication. ${ }^{78}$ The mechanistic bases for these global replication roles have not been defined, but Okazaki fragment processing per se is probably not the culprit since loss of flap endonuclease 1 does not slow forks. ${ }^{113}$ Less direct effects cannot be ruled out. For example, BLM deficiency can lead to pyrimidine pool imbalances that themselves can independently affect fork rate. ${ }^{114}$ These pool imbalances may, in turn, reflect the role of $\mathrm{BLM}^{68}$ and $\mathrm{WRN}$ in regulating gene expression required for S-phase progression (RJM Jr, manuscript in preparation).

\section{Specialized roles in replication - common fragile sites, telomeres, and G4 DNAs}

RECQ helicases also play important - and potentially critical - roles in the replication of genomic regions that are intrinsically difficult to replicate. Examples include common fragile sites (CFSs), telomeres, and other repeated sequences, in particular those with high G4-forming potential. CFS chromosomal fragility can be exacerbated by suppressing fork progression rates and may reflect an increased probability of fork breakage or fork cleavage ${ }^{115,116}$ resulting from 1) secondary DNA structures including G4 DNA; 
2) a paucity of replication initiation sites; and 3) collisions with RNA polymerases that may be actively transcribing or stalled in the large genes found at many CFSs (reviewed in Franchitto ${ }^{117}$ ). Without WRN ${ }^{118}$ or BLM, ${ }^{119}$ CFS fragility is enhanced, whereas RECQL can bind CFSs under conditions of "replication stress" (see below). ${ }^{103}$

RECQ helicases also function in telomere replication and maintenance. Telomeric DNA poses a dual challenge to the DNA replication machinery by virtue of the repeated, GC-rich and G4-prone nature of telomeric repeats (TTAGGG in humans), together with the unique chromatin structure formed at chromosome ends. This chromosomal "cap" consists of a telomeric repeat T-loop stabilized by telomere-associated proteins. ${ }^{120,121}$ Moreover, due to the unidirectional nature of fork travel at telomeric ends (centromere $>$ telomere), the G-rich DNA strand is always the lagging strand with ssDNA stretches that may form G4 DNA. Cells lacking any of four RECQ proteins - RECQL, ${ }^{122}$ RECQL4, ${ }^{123}$ WRN (reviewed in Opresko ${ }^{124}$ ), or BLM $^{98,120}$ - all show telomere breakage and loss, consistent with the notion that these RECQs help unwind and restructure telomeres to facilitate replication. This was demonstrated at the molecular level for WRN, where its helicase activity was required for complete replication of the G-rich lagging strand of telomeric DNA. ${ }^{125,126}$ A substantial percentage of tumor cells lack telomerase and only gain a measure of replicative immortality by use of a recombination-mediated "alternative lengthening of telomeres" pathway. The alternative lengthening of telomere pathway utilizes HR activities and involves both WRN and BLM (reviewed in Bhattacharyya et al, ${ }^{127}$ Mendez-Bermudez et al, ${ }^{128}$ and Edwards et $\mathrm{al}^{129}$ ).

\section{Replication stress - when good forks go bad}

A remarkably broad range of chemical, physical, and genetic perturbations can slow or disrupt replication forks to give rise to "replication stress". ${ }^{130,131}$ A common experimental example is to treat cells with the ribonucleotide reductase inhibitor hydroxyurea in order to deplete nucleotide pools and arrest forks. Hydroxyurea-mediated arrest stalls forks globally, though leaves them largely intact and able to resume DNA synthesis (or 'restart') by recruiting or re-engaging DNA polymerases and other proteins including WRN ${ }^{110,132-135}$ and BLM. ${ }^{110,136}$ Replication fork maintenance and protection during replication stress, often termed "remodeling", shares many features with the DSB repair pathways discussed above, despite having a different intended goal: to "prevent" fork breakage. Fork remodeling includes RECQ-dependent, reversible DNA strand exchange, and strand resection steps followed by resynthesis (extension). The strand exchanges are from parental-nascent to nascent-nascent strand duplexes and back, leading to fork regression and its reversal (Figure 2). Resection can occur on either duplex. These and other remodeling reactions promote fork persistence by 1) generating ssDNA to activate checkpoint signaling and thus alert the cell to replication blocks; 2) reloading proliferating cell nuclear antigen or related polymerase "clamps"; and 3) recruiting or engaging replicative or specialized DNA polymerases to resume replication or promote lesion bypass.

"Dead end" forks - those that cannot be repaired or remodeled to facilitate restart - can be rescued by endonucleolytic cleavage to generate DNA ends for the DSB repair pathways discussed above. Both the helicase and exonuclease activities of WRN are likely involved, ${ }^{135}$ while the BLM dissolvasome may remove topological linkage between sister DNA duplexes generated in the course of strand exchanges. A recent study that combined highresolution molecular and cellular analyses demonstrated that RECQL is specifically required to reverse regressed forks stalled by camptothecin-induced topoisomerase I inhibition. ${ }^{12}$

\section{Mitochondrial DNA maintenance}

Among the RECQ helicase proteins, RECQL4 appears to have an important extranuclear role in mitochondrial DNA maintenance. Evidence supporting this idea is the reversible, regulated localization of RECQL4 to the nucleus or cytoplasm $^{137,138}$; the interaction of RECQL4 and TP53 protein to promote mitochondrial import of both proteins and their binding to DNA polymerase gamma with modulation of polymerase biochemical activities ${ }^{139,140}$; and the accumulation of mitochondrial DNA damage in RECQL4-deficient cells. ${ }^{141}$

\section{DNA transcription}

The loss of WRN, BLM, or RECQL function perturbs gene and microRNA (miRNA) expression. Gene expression changes in WRN- and BLM-deficient cells preferentially occur in genes with high G4 DNA-forming potential, thus providing compelling evidence that G4 DNA elements are indeed physiologic substrates for RECQ helicases in living cells..$^{68,142,143}$ These changes in gene expression are providing new insight into RECQ helicase function and disease pathogenesis (see below). RECQL5, in contrast, was found to slow transcription elongation and limit transcription errors. ${ }^{40,59} \mathrm{~A}$ final intriguing connection between gene G4-forming potential, replication, and gene expression was revealed by the Sale laboratory (Sarkies et al), ${ }^{144,145}$ in which the presence of G4-forming DNA elements 


\section{A Double strand break repair}

B Replication fork remodeling

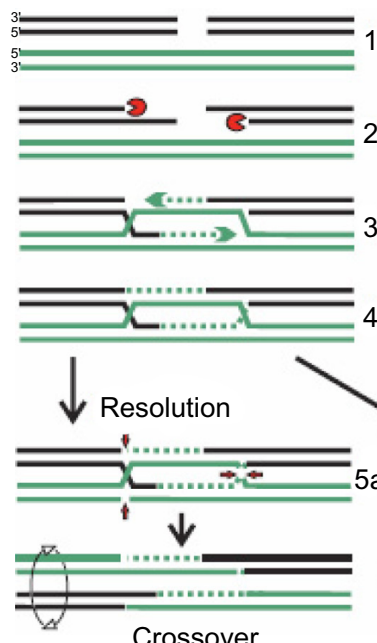

Crossover
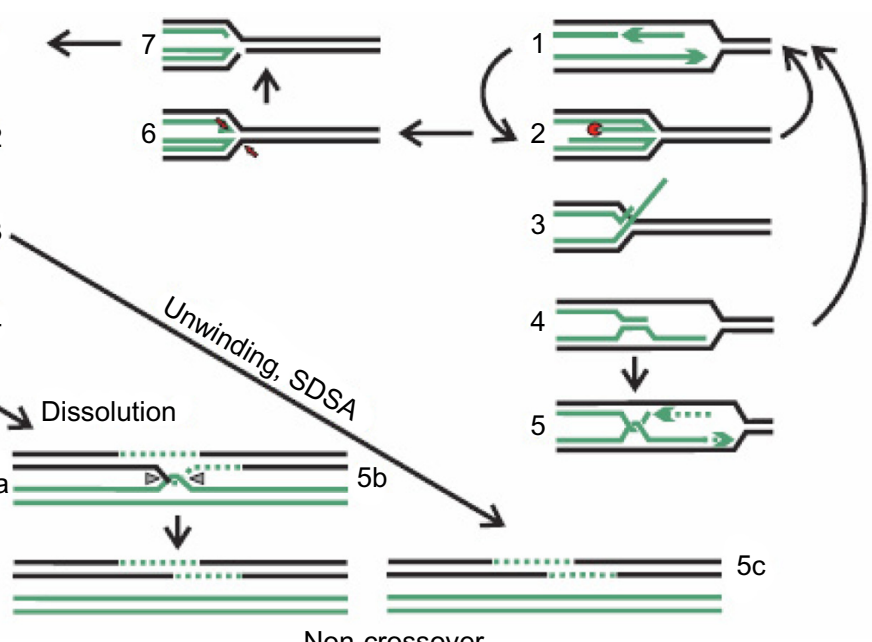

Non-crossover

Figure 2 DNA metabolic pathways for DSB repair by homologous recombination and for stabilization and remodeling of stalled replication forks.

Notes: (A) A DSB in DNA (step I) can be directly rejoined (by NHEj; not shown), or resected at both ends to expose $3^{\prime}$ single-stranded overhangs (step 2). The overhang can then pair with a homologous donor sequence on a sister chromatid or elsewhere, forming a displacement, or D-loop. The invading 3' end in a D-loop uses the donor sequence as a template to prime synthesis of a stretch of DNA that overlaps the original breakpoint (step 3). The second $3^{\prime}$ overhang of the DSB can be captured by the free strand of the D-loop and prime synthesis of complementary DNA. The resulting structure is termed a double HJ (step 4). Each of the four-strand junctions in a double HJ can be resolved, ie, symmetrically cleaved in two ways (marked by arrows) and ligated. One of the cleavage-rejoin options results in crossing over, ie, joining of donor and recipient DNA duplexes (step 5a). A double $\mathrm{HJ}$ can also be dissolved by migrating its two branch points toward each other (marked by arrowheads), then using topoisomerase to eliminate the topological linkage between the catenated DNA strands ( $(\mathrm{step} 5 \mathrm{~b}$ ). Alternatively, newly synthesized DNA strands can be released from the donor-recipient DNA heteroduplex and anneal with each other to restore DNA integrity, a pathway termed synthesis-dependent strand annealing or SDSA (step 5c). (B) A stalled replication fork can regress, ie, undergo a reversible strand exchange whereby nascent strands pair with each to form a forked structure termed a "chicken foot" (steps I-2). Alternatively, a nascent strand duplex can be resected (similar to step 2 in DSB repair) to generate a free $3^{\prime}$ single-stranded DNA end (step 3). This single-stranded DNA can invade the parent strand duplex in a process similar to the D-loop formation (step 4) to prime DNA synthesis. Depending on the extent of regression and resection, some nascent strand pairing may remain behind and can be dissolved in the same manner as a double $\mathrm{HJ}$ (compare step 5 with step $5 \mathrm{~b}$ in DSB repair). Prolonged fork stalling and/or futile cycles of regression/resection can lead to fork breakage with resolution of the chicken foot intermediate in a manner similar to HJ resolution (compare step 6 with step 5 a in DSB repair) with the generation of a one-sided DSB (step 7). Broken forks thereby become substrates for DSB repair activities.

Abbreviations: DSB, double-strand break; HJ, Holliday junction; NHEJ, nonhomologous DNA end joining; SDSA, synthesis-dependent strand annealing.

led to a requirement for WRN or BLM to enable replication and maintain expression-promoting chromatin marks. These results suggest that the absence of RECQ function may further perturb cells by contributing to replication-dependent epigenetic instability. ${ }^{144,145}$

\section{Regulation of RECQ helicase activities}

The regulation of RECQ function through a combination of posttranslational modification, localization, and proteinprotein association is a very active area of research, where we

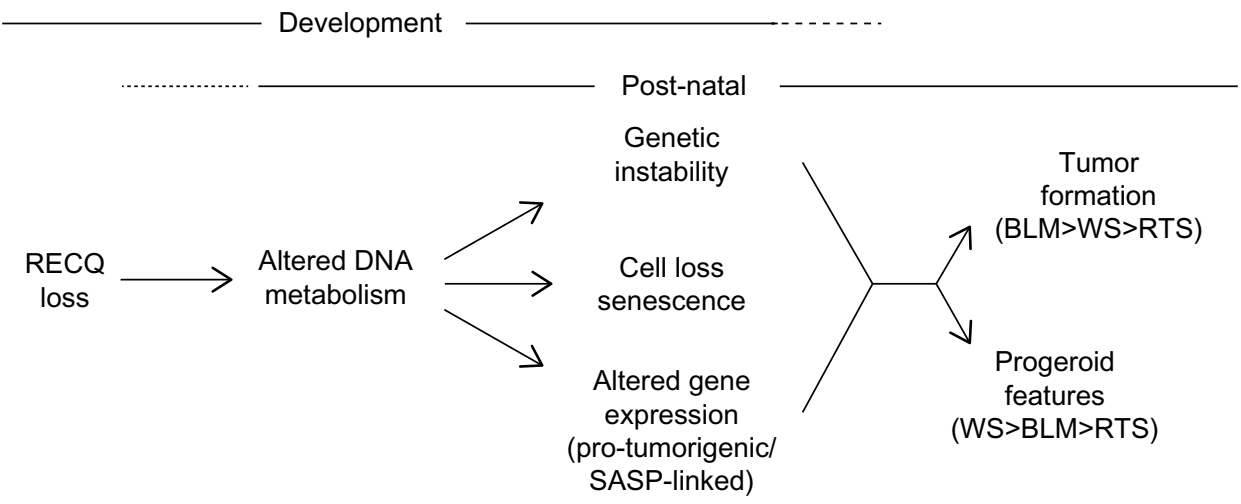

Figure 3 Pathogenesis of RECQ helicase deficiency syndromes.

Notes: Heritable loss of RECQ function leads to altered DNA metabolism in most or all cell lineages during and after development. Altered or aberrant DNA metabolism, in turn, leads to genetic instability, cell loss or senescence, and altered gene expression, where affected genes are highly enriched in gene G4 DNA elements. These altered genes map to molecular and cellular functions such as cell growth, proliferation, and survival; canonical pathways, eg, in Bloom syndrome (BLM) patients promoting cancer; and networks affecting tissue-level structure, function, and maintenance, eg, connective tissue networks and genes associated with the senescence-associated secretory phenotype (SASP) in Werner syndrome (WS). The balance of these consequences of loss of function determines the mix of proliferative (tumor formation) and abiotrophic (progeroid) outcomes in individual RECQ deficiency syndromes and in patients with BLM, WS, or Rothmund-Thomson syndrome (RTS). 
still have only the beginnings of an outline of the regulatory networks that modulate RECQ helicase activity in cells. The following section focuses on posttranslational modification and several instances where modification and localization are associated.

\section{Posttranslational modification}

The RECQ helicase proteins are subject to several different types of posttranslational modifications that govern activity, localization, and protein-protein association. The most extensively developed lines of mechanistic evidence are summarized below and discussed in greater detail elsewhere (eg, Croteau et $\mathrm{al}^{4}$ ).

\section{Phosphorylation}

The ATM and ATR kinases, key components of the response to DNA damage and replication stress, respectively, phosphorylate six S/TQ residues in WRN. WRN phosphorylation by ATR on residues S991, T1152, and S1256 promotes the retention of WRN at stalled forks to preserve their ability to restart replication (see above). Prolonged fork arrest results in MUS81-dependent cleavage ${ }^{132,135}$ to generate DSB ends that trigger ATM-dependent WRN phosphorylation on residues S1058, S1141, and S1292. These alternative phospho-states may facilitate the switch from a replicative to DSB repair mode, with dissociation of WRN from DSB sites. ${ }^{134,135,146}$ WRN is also phosphorylated by DNA-PK cs and ABL tyrosine kinase, acetylated, and can be associated with SUMO-1, providing additional opportunities for regulation.

\section{SUMOylation}

BLM undergoes both constitutive and conditional phosphorylation. These changes are likely to play a role in the targeting and activation of BLM in response to DNA damage, replication stress, and mitotic cycling (reviewed in Böhm and Bernstein ${ }^{147}$ ). The modification of BLM residues K317 and K331 by SUMO (sumoylation) after prolonged, DSB-inducing fork arrest may switch BLM from DSB avoidance to a DSB repair mode. ${ }^{148,149}$ This switch may be mediated via decreased association of sumoylated BLM with RPA, together with increased binding to RAD51. ${ }^{150}$ Finally, ubiquitylation of BLM appears to play a role in both the response to replication stress and nuclear partitioning. ${ }^{151}$

\section{Poly(ADP-ribose) polymerase I and poly(ADP-ribose)}

Another important example of the regulation of RECQ protein-protein association and functional regulation involves
poly(ADP-ribose) polymerase (PARP)-1. PARP-1 is a major PARP in human cells that was initially implicated in base excision repair and single strand break repair but is now known to be involved in virtually every DNA repair pathway as well as in replication stress response and checkpoint signaling. This central role for PARP-1 also suggests it may be an important target in cancer chemotherapy. ${ }^{152}$ The current model for PARP-1 function in DNA repair has it acting as a "first responder" to DNA breaks and lesions, where it binds discontinuities in the phosphate backbone of DNA to trigger auto- and trans-PARylation. Poly(ADP-ribose) (PAR) groups on PARP-1 and other proteins then serve to recruit additional signaling and repair proteins which bind PAR groups via several types of PAR recognition motifs.

An interesting exception to this widely accepted general model are the RECQ proteins. RECQ helicases do not appear to be substrates of PARP-1 or be recruited by PARylated PARP-1 to DNA. ${ }^{101,153}$ Instead, WRN was shown to bind free PAR (which is cleaved off PARP-1 and targets by PARG) via a newly identified PAR-binding motif in the WRN exonuclease domain. ${ }^{154}$ This may dissociate WRN and enable downregulating the DNA damage response. In contrast, WRN and RECQL physically associate with PARP-1 in the absence of DNA. ${ }^{12,153,155}$ There are also data from mice that the productive interaction of Wrn and Parp-1 is genome stabilizing and can antagonize both karyotypic rearrangements and cancer. ${ }^{156}$ While these associations have been well-documented, functional consequences of WRN binding to PARP-1 remain a matter of debate. ${ }^{153,157}$ A better understood example is RECQL association with PARP-1. This association is enhanced by camptothecin (CPT)-induced PARylation of PARP- $1^{112}$ and inhibits the ability of RECQL to reverse regressed replication forks in vitro. This fits well with the observed behavior of replication forks in CPT-treated, RECQL-depleted cells treated with PARP inhibitors. ${ }^{12}$ Further research will be required to integrate this mechanistically elegant story into a broader context of PARP-1 function in replication and in repair.

Global levels of PARylation in response to oxidative damage have been investigated in WS cells and in WRN-, RECQL-, and RECQL5-depleted cells. These analyses found a less consistent downregulation of PARylation in WRN-depleted cells than was initially observed in WS cells. ${ }^{155}$ Subsequent analyses of WRN-depleted cells showed variable, weak effects. RECQL5 and RECQL-depleted cells showed, respectively, constitutive or damage-induced hyperactivation of PARylation, ${ }^{101,102}$ which supports their roles in single strand break repair and base excision repair. 


\section{Acetylation}

Two of the human RECQ helicases, WRN and RECQL4, have been shown to be acetylated. In the case of WRN, acetylation appears to modulate both catalytic activity and localization. ${ }^{158,159}$ The histone acetyltransferase p300 acetylates RECQL4 at up to five different lysine residues contained in a 30-residue stretch of RECQL4 that is required for nuclear localization. RECQL4 acetylation by p300 disrupts nuclear import and leads to the cytoplasmic accumulation of RECQL4. ${ }^{137}$

There are undoubtedly other posttranslational modifications of RECQ helicase proteins in addition to the few that have been cataloged above. It should be possible to catalog these using both mass spectrometry-based analytical approaches and tie specific modifications to biological activities by the use of a combination of conditional mutant proteins in conjunction with high-resolution functional assays.

\section{From biochemistry to phenotype}

The sections above emphasize both the diverse roles of RECQ helicases in DNA metabolism, and the absence of a simple one-to-one mapping of individual RECQ helicases to specific pathways or processes. The human RECQ deficiency syndromes further emphasize that despite their biochemical similarities, the human RECQ helicases are not functionally interchangeable in cells. A focus for research in the immediate future is to elucidate the details of molecular cooperativity and functional redundancy, while identifying potentially unique in vivo roles of each human RECQ helicase.

The human RECQ helicases are ubiquitously expressed in most or all cell lineages. Thus, the consequences of loss of RECQ function - reduced cell proliferation, DNA damage sensitivity, genetic or genomic instability, and altered gene expression - have the potential to disrupt organismal DNA metabolism both during and after development. The biochemical properties and DNA metabolic functions of the human RECQ helicases discussed above provide mechanistic insight into the origins of these cellular phenotypes and serve as the basis for a conceptual model to link molecular and cellular defects to the pathogenesis of the RECQ helicase deficiency syndromes (Figure 3).

WRN-deficient cells display a proliferative defect that reflects a combination of cell cycle abnormalities with longer cell cycle times, especially in response to DNA damage, a reduced growth fraction, and high levels of cellular senescence. ${ }^{110,111,160,161}$ Similar defects have been observed in BLMdeficient cells, where the depletion of BLM has a stronger growth-suppressive effect than comparable levels of depletion of WRN. ${ }^{162,163}$ Human cells depleted of RECQL and RECQL4 also display reduced proliferation in culture. ${ }^{39,43}$

These proliferative defects provide a partial explanation for why BS and RTS patients are typically born small, though they are proportionately developed. This is particularly striking in BS patients, who are born and typically remain at or below the fifth percentile for height and weight. ${ }^{164}$ DNA replication defects in BS and RTS may lead directly to this organismal phenotype by reducing the number of cells required for development that as a process is otherwise largely normal. The proliferative defects that accompany BLM or RECQL4 loss are more marked than for WRN, which may explain the lack of a strong developmental component as part of the WS clinical phenotype.

The progressive development of progeroid features in WS may reflect postdevelopmental roles for WRN in tissue maintenance. Disrupted DNA metabolism in the absence of WRN may lead to persistent DNA damage signaling and genetic instability with the accumulation of mutant and senescent cells. ${ }^{161,165}$ This progressive accumulation of underperforming cells could further compromise tissue structure and function if accompanied by a local and/or systemic senescent cell-associated secretory phenotype. ${ }^{166}$ The age-dependent accumulation of senescent cells has been documented in aging primates, ${ }^{167,168}$ and one testable prediction of our model is that senescent cells are present at elevated levels in WS patients and perhaps in BS and RTS patients.

A second ominous consequence of persistent genetic instability, epigenetic drift, and cell loss is the potential for the emergence of cancer. Cellular senescence in the RECQ helicase syndromes may have one modest silver lining: senescence is an effective, albeit nonspecific, tumorsuppressive mechanism, even in the face of persistent genetic instability. ${ }^{165,169}$ A systematic comparison of genetic and epigenetic alterations in tumors common to WS, BS, and RTS such as osteosarcoma, or unique to one of the syndromes such as acral lentiginous melanoma in WS, might identify mutations or pathways that promote specific neoplasms in RECQ-deficient individuals.

Cells are not passive bystanders when DNA metabolism is disrupted, and as noted above, persistent DNA damage signaling is likely to be an important driver of RECQ cellular phenotypes. An unresolved question is the extent to which disease pathogenesis is driven by RECQ-dependent DNA metabolic defects as opposed to damage signaling or other potentially adaptive responses. We have begun to address this question by quantifying gene and miRNA expression 
in BS and WS patient cells and contrasting these changes with comparable profiling data from fibroblasts depleted of WRN or BLM. These analyses have already revealed several intriguing general conclusions: 1) the expression of many $(>1,000)$ genes and dozens of miRNAs is reproducibly altered when WRN or BLM function is lost by mutation or depletion; 2) many of these RECQ-dependent gene expression changes are strongly correlated with the presence of G4 DNA elements in the 5 '-end of the altered genes; 3 ) genes whose expression is altered by WRN or BLM deletion are enriched in DNA metabolic pathways in which RECQ helicases participate; and 4) genes and miRNAs whose expression is altered in WS and/or BS patient cells are strongly enriched for fundamental molecular and cellular processes such as cell growth, proliferation, death, or survival, together with canonical pathways that promote tumorigenesis or tumor type-specific signaling (Nguyen et al ${ }^{68}$ and Tang, Robles et al [unpublished data]).

These results begin to provide a nuanced view of how RECQ loss alters DNA metabolism, signaling, and gene expression, changes that over time lead to a constellation of broadly adaptive gene and miRNA expression changes that themselves promote the pathogenesis of acquired diseases including cancer.

\section{Broader roles for RECQ helicases in human disease?}

An important unanswered question is what role RECQ helicases play in diseases outside of the WS-, BS-, and RTS-deficiency syndromes. Carriers for the recessive RECQ helicase deficiency syndromes are prevalent in the general population: for example, $W R N$ mutation carriers have an estimated frequency of $1 / 250$ in the US population, and there are $\sim 1.5 \times 10^{6}$ mutation carriers in the US population alone. Individuals in WS pedigrees who are heterozygous for pathogenic $W R N$ mutations have in vivo genetic instability, ${ }^{170}$ and cell lines from these individuals show intermediate sensitivity to killing by DNA-damaging chemotherapeutic agents that selectively kill WRN-deficient cells. ${ }^{171,172}$ Given their frequency and large number, an important question is whether $W R N$ mutation carriers are at elevated risk of cancer, therapy-related toxicity, or other diseases.

RECQ somatic mutations also have the potential to contribute to disease, though they have been infrequently reported in human tumors. One supposition is that RECQ mutations that lead to loss of function are actively selected against early in tumor progression. Loss, silencing, or altered expression of RECQ genes, in contrast, may be frequent in many tumor types including common adult epithelial cancers such as breast and colorectal cancer. ${ }^{173}$ Promoter region and gene body methylation have been suggested as one cause for loss of WRN expression in human tumors. ${ }^{174-176}$ However, the relationship between methylation and loss of expression does not appear to be consistent enough in our and in others' hands to be useful alone as a surrogate expression marker (Bosch et al, unpublished results). Identifying RECQ expression loss in tumors is practically important, as the level of expression may be a useful therapeutic biomarker of drug sensitivity. ${ }^{163}$

The RECQ helicase proteins themselves may be direct targets for the treatment of cancer or other diseases. The helicase and, in the case of WRN the exonuclease, catalytic activities of the human RECQ helicases provide ready targets for newly identified small-molecule inhibitors..$^{3,177,178}$ The direct targeting of tumors with RECQ helicase inhibitors might, in addition, provide a clear, tumor-specific therapeutic advantage if combined with conventional chemotherapy. ${ }^{3}$ The targeting of survival pathways specific to one - or common to several - RECQ helicase could provide a second approach to improve the therapy of patients with tumor-specific RECQ defects. ${ }^{179-182}$ These pathways have been identified in part by the recent gene expression-profiling experiments described above and could be further interrogated by focused RNA inhibition or drug/small-molecule screens.

\section{Conclusion}

Loss of function of three different members of the human RECQ helicase family, BLM, WRN, and RECQL4, leads to distinct diseases with developmental and acquired features including a markedly elevated risk of specific cancers. These "experiments of nature" have provided useful insights into the physiologic roles of the human RECQ helicases and how a loss of function leads to DNA metabolic defects together with adaptive changes that jointly drive disease pathogenesis.

\section{Acknowledgments}

Work in the authors' laboratories has been supported by grants from the US National Institutes on Aging, Cancer and Environmental Health Sciences, together with the Nippon Boehringer Ingelheim Virtual Research Institute of Aging. The authors acknowledge the help provided by the laboratory members and colleagues who have contributed many of the ideas and hard work that made this review possible and to Keffy Kehrli for proofing the completed manuscript. 


\section{Disclosure}

JMS and RJM Jr, have no relevant conflicts of interest to declare.

\section{References}

1. Singleton MR, Dillingham MS, Wigley DB. Structure and mechanism of helicases and nucleic acid translocases. Annu Rev Biochem. 2007;76: 23-50.

2. Vindigni A, Marino F, Gileadi O. Probing the structural basis of RecQ helicase function. Biophys Chem. 2010;149:67-77.

3. Brosh RM Jr. DNA helicases involved in DNA repair and their roles in cancer. Nat Rev Cancer. 2013;13:542-558.

4. Croteau DL, Popuri V, Opresko PL, Bohr VA. Human RecQ helicases in DNA repair, recombination, and replication. Annu Rev Biochem. 2014;83:519-552.

5. Bloom D. Congenital telangiectatic erythema resembling lupus erythematosus in dwarfs. Am J Dis Child. 1954;88:754-758.

6. German J. Bloom syndrome: a Mendelian prototype of somatic mutational disease. Medicine (Baltimore). 1993;72:393-406.

7. German J. Bloom's syndrome. VIII. Review of clinical and genetic aspects. In: Goodman RM, Motulsky AG, editors. Genetic Diseases Among Askenazi Jews. Vol 1. New York: Raven Press; 1979 121-139.

8. German J. Bloom's syndrome: XX. The first 100 cancers. Cytogenet Cell Genet. 1997;93:100-106.

9. Epstein CJ, Martin GM, Schultz AL, Motulsky AG. Werner's syndrome: a review of its symptomatology, natural history, pathologic features, genetics and relationship to the natural aging process. Medicine. 1966;45:177-221.

10. Goto M. Hierarchical deterioration of body systems in Werner's syndrome: implications for normal ageing. Mech Ageing Dev. 1997;98: 239-254.

11. Monnat RJ Jr. Werner syndrome as a model of human aging. In: Conn PM, editor. Handbook of Models for Human Aging. Vol 1. Amsterdam: Elsevier Academic Press; 2006:961-976.

12. Tollefsbol TO, Cohen HJ. Werner's syndrome: an underdiagnosed disorder resembling premature aging. Age. 1984;7:75-88.

13. Werner $\mathrm{O}$. On cataract in conjunction with scleroderma (translated by H Hoehn). In: Salk D, Fujiwara Y, Martin GM, editors. Werner's Syndrome and Human Aging; Advances Experimental Medicine and Biology. Vol. 190. New York: Plenum Press; 1985:1-14.

14. Goto M, Miller RW, Ishikawa Y, Sugano H. Excess of rare cancers in Werner syndrome (adult progeria). Cancer Epidemiol Biomarkers Prev. 1996;5:239-246.

15. Lauper JM, Krause A, Vaughan TL, Monnat RJ Jr. Spectrum and risk of neoplasia in Werner syndrome: a systematic review. PLoS One 2013;8:e59709.

16. Lauper JM, Monnat RJ Jr. Diabetes mellitus and cancer in Werner syndrome. Acta Diabetol. 2013;51:159-161.

17. Monnat RJ Jr. Werner syndrome. In: Fletcher CDM, Bridge JA, Hogendoorn PCW, Mertens F, editors. WHO/IARC Monograph on Pathology and Genetics of Tumours of Soft Tissue and Bone. 4th ed. Lyon: IARC Press; 2013:393-394.

18. Huang S, Lee L, Hanson NB, et al. The spectrum of WRN mutations in Werner syndrome patients. Hum Mutat. 2006;27:558-567.

19. Hisama FM, Kubisch C, Martin GM, Oshima J. Clinical utility gene card for: Werner syndrome. Eur J Hum Genet. Epub 2012 January 18.

20. Goto M, Ishikawa Y, Sugimoto M, Furuichi Y. Werner syndrome: a changing pattern of clinical manifestations in Japan (1917-2008). BioSci Trends. 2013;7:13-22.

21. Rothmund A. Ueber cataracten in verbindung mit einer eigentmlichen hautdegeneration. Arch Klin Exp Ophtal. 1868;14:159-182. German.

22. Thomson MS. Poikiloderma congenitale. [Congenital poikiloderma]. Br J Dermatol. 1936;48: 221-234.
23. Taylor WB. Rothmund's syndrome-Thomson's syndrome: congenital poikiloderma with and without juvenile cataracts. A review of the literature, report of a case, and discussion of the relationship of the two syndromes. AMA Arch Dermatol. 1957;75:236-244.

24. Larizza L, Roversi G, Volpi L. Rothmund-Thomson syndrome. Orphanet J Rare Dis. 2010;5:2.

25. Wang LL, Levy ML, Lewis RA, et al. Clinical manifestations in a cohort of 41 Rothmund-Thomson syndrome patients. Am J Hum Genet. 2001;102:11-17.

26. Siitonen HA, Sotkasiira J, Biervliet M, et al. The mutation spectrum in RECQL4 diseases. Eur J Hum Genet. 2009;17:151-158.

27. Wang LL, Gannavarapu A, Kozinetz CA, et al. Association between osteosarcoma and deleterious mutations in the RECQL4 gene in Rothmund-Thomson syndrome. J Natl Cancer Inst. 2003;95:669-674.

28. Lu L, Jin W, Liu H, Wang L. RECQ DNA helicases and osteosarcoma. In: Kleinerman MDES, editor. Current Advances in Osteosarcoma. Vol 804. Cham, Switzerland: Springer International Publishing; 2014:129-145.

29. Van Maldergem L, Siitonen HA, Jalkh N, et al. Revisiting the craniosynostosis-radial ray hypoplasia association: Baller-Gerold syndrome caused by mutations in the RECQL4 gene. J Med Genet. 2006;43:148-152.

30. Siitonen HA, Kopra O, Kääriäinen H, et al. Molecular defect of RAPADILINO syndrome expands the phenotype spectrum of RECQL diseases. Hum Mol Genet. 2003;12:2837-2844.

31. Larsen NB, Hickson ID. RecQ helicases: conserved guardians of genomic integrity. Adv Exp Med Biol. 2013;767:161-184.

32. Ellis NA, Groden J, Ye TZ, et al. The Bloom's syndrome gene product is homologous to RecQ helicases. Cell. 1995;83:655-666.

33. Yu CE, Oshima J, Fu YH, et al. Positional cloning of the Werner's syndrome gene. Science. 1996;272:258-262.

34. Monnat RJ Jr. Werner syndrome: molecular genetics and mechanistic hypotheses. Exp Gerontol. 1992;27:447-453.

35. Kitao S, Shimamoto A, Goto M, et al. Mutations in RECQ4L cause a subset of cases of Rothmund-Thomson syndrome. Nat Genet. 1999;22: $82-84$.

36. Kitao S, Ohsugi I, Ichikawa K, Goto M, Furuichi Y, Shimamoto A. Cloning of two new human helicase genes of the RecQ family: biological significance of multiple species in higher eukaryotes. Genomics. 1998;54:443-452.

37. Puranam KL, Blackshear PJ. Cloning and characterization of RecQL, a potential human homologue of the Escherichia coli DNA helicase RecQ. J Biol Chem. 1994;269:29838-29845.

38. Seki M, Miyazawa H, Tada S, et al. Molecular cloning of cDNA encoding human DNA helicase Q1 which has homology to Escherichia coli RecQ helicase and localization of the gene at chromosome 12p12. Nucleic Acids Res. 1994;22:4566-4573.

39. Sharma S, Stumpo DJ, Balajee AS, et al. RECQL, a member of the RecQ family of DNA helicases, suppresses chromosomal instability. Mol Cell Biol. 2007;27:1784-1794.

40. Saponaro M, Kantidakis T, Mitter R, et al. RECQL5 controls transcript elongation and suppresses genome instability associated with transcription stress. Cell. 2014;157:1037-1049.

41. Aygün O, Svejstrup JQ. RECQL5 helicase: connections to DNA recombination and RNA polymerase II transcription. DNA Repair. 2010;9: 345-353.

42. Aygün O, Svejstrup J, Liu Y. A RECQ5-RNA polymerase II association identified by targeted proteomic analysis of human chromatin. Proc Natl Acad Sci U SA. 2008;105:8580-8584.

43. Thangavel S, Mendoza-Maldonado R, Tissino E, et al. The human RECQ1 and RECQ4 helicases play distinct roles in DNA replication initiation. Mol Cell Biol. 2009;30:1382-1396.

44. German J, Sanz MM, Ciocci S, Ye TZ, Ellis NA. Syndrome-causing mutations of the BLM gene in persons in the Bloom syndrome registry. Hum Mutat. 2007;28:743-753.

45. Goto M, Yamabe Y, Shiratori M, et al. Immunological diagnosis of Werner syndrome by down-regulated and truncated gene products. Hum Genet. 1999;105:301-307. 
46. Moser MJ, Kamath-Loeb AS, Jacob JE, Bennett SE, Oshima J, Monnat RJ Jr. WRN helicase expression in Werner syndrome cell lines. Nucleic Acids Res. 2000;28:648-654.

47. Swanson C, Saintigny Y, Emond MJ, Monnat RJ Jr. The Werner syndrome protein has separable recombination and viability functions. DNA Repair. 2004;3:475-482.

48. Saintigny Y, Makienko K, Swanson C, Emond MJ, Monnat RJ Jr. Homologous recombination resolution defect in Werner syndrome. Mol Cell Biol. 2002;22:6971-6978.

49. Friedrich K, Lee L, Leistritz DF, et al. WRN mutations in Werner syndrome patients: genomic rearrangements, unusual intronic mutations and ethnic-specific alterations. Hum Genet. 2010;128:103-111.

50. Wang LL, Worley K, Gannavarapu A, Chintagumpala MM, Levy ML, Plon SE. Intron-size constraint as a mutational mechanism in RothmundThomson syndrome. Am J Hum Genet. 2002;71:165-167.

51. Tanaka S, Umemori T, Hirai K, Muramatsu S, Kamimura Y, Araki H. CDK-dependent phosphorylation of Sld2 and Sld3 initiates DNA replication in budding yeast. Nature. 2007;445:328-332.

52. Gaggioli V, Zeiser E, Rivers D, Bradshaw CR, Ahringer J, Zegerman P. CDK phosphorylation of SLD-2 is required for replication initiation and germline development in C elegans. J Cell Biol. 2014;204:507-522.

53. Kamath-Loeb AS, Welcsh P, Waite M, Adman ET, Loeb LA. The enzymatic activities of the Werner syndrome protein are disabled by the amino acid polymorphism R834C. J Biol Chem. 2004;279:55499-55505.

54. Monnat RJ Jr. Human RECQ helicases: roles in DNA metabolism, mutagenesis and cancer biology. Semin Cancer Biol. 2010;20:329-339.

55. Masai H. RecQL4: a helicase linking formation and maintenance of a replication fork. J Biochem. 2011;149:629-631.

56. Sharma S. Non-B DNA secondary structures and their resolution by RecQ helicases. J Nucleic Acids. 2011;2011:724215.

57. Croteau DL, Singh DK, Hoh Ferrarelli L, Lu H, Bohr VA. RECQL4 in genomic instability and aging. Trends Genet. 2012;28:624-631.

58. Rezazadeh S. RecQ helicases; at the crossroad of genome replication, repair, and recombination. Mol Biol Rep. 2012;39:4527-4543.

59. Popuri V, Tadokoro T, Croteau DL, Bohr VA. Human RECQL5: guarding the crossroads of DNA replication and transcription and providing backup capability. Crit Rev Biochem Mol Biol. 2013;48:289-299.

60. Sami F, Sharma S. Probing genome maintenance functions of human RECQ1. Comput Struct Biotechnol J. 2013;6:e201303014.

61. Suhasini AN, Brosh RM Jr. DNA helicases associated with genetic instability, cancer, and aging. Adv Exp Med Biol. 2013;767:123-144.

62. Ha T, Kozlov AG, Lohman TM. Single-molecule views of protein movement on single-stranded DNA. Annu Rev Biophys. 2012;41:295-319.

63. Yodh JG, Stevens BC, Kanagaraj R, Janscak P, Ha T. BLM helicase measures DNA unwound before switching strands and hRPA promotes unwinding reinitiation. EMBO J. 2009;28:405-416.

64. Klaue D, Kobbe D, Kemmerich F, Kozikowska A, Puchta H, Seidel R. Fork sensing and strand switching control antagonistic activities of RecQ helicases. Nat Commun. 2013;4:2024.

65. Maizels N. Quadruplexes and the biology of G-rich genomic regions. In: Neidle S, Balasubramanian S, editors. Quadruplex Nucleic Acids. Cambridge: Royal Society of Chemistry Publishing; 2006:228-252.

66. Eddy J, Vallur AC, Varma S, et al. G4 motifs correlate with promoterproximal transcriptional pausing in human genes. Nucleic Acids Res. 2011;39:4975-4983.

67. Maizels N, Gray LT. The G4 genome. PLoS Genet. 2013;9: e1003468.

68. Nguyen GH, Tang W, Robles AI, et al. Regulation of gene expression by the BLM helicase correlates with the presence of G-quadruplex DNA motifs. Proc Natl Acad Sci U S A. 2014;111:9905-9910.

69. Suzuki N, Shimamoto A, Imamura O, et al. DNA helicase activity in Werner's syndrome gene product synthesized in a baculovirus system. Nucleic Acids Res. 1997;25:2973-2978.

70. Huang S, Li B, Gray MD, Oshima J, Mian IS, Campisi J. The premature aging syndrome protein, WRN, is a $3^{\prime}$ to $5^{\prime}$ exonuclease. Nat Genet. 1998;20:114-116.
71. Kamath-Loeb AS, Shen JC, Loeb LA, Fry M. Werner syndrome protein II: characterization of the integral $3^{\prime}->5^{\prime}$ DNA exonuclease. J Biol Chem. 1998;273:34145-34150.

72. Shen JC, Gray MD, Oshima J, Kamath-Loeb AS, Fry M, Loeb LA. Werner syndrome protein I: DNA helicase and DNA exonuclease reside on the same polypeptide. J Biol Chem. 1998;273:34139-34144.

73. Shen JC, Gray MD, Oshima J, Loeb LA. Characterization of Werner syndrome protein DNA helicase activity: directionality, substrate dependence and stimulation by replication protein A. Nucleic Acids Res. 1998;26:2879-2885.

74. Huang S, Beresten S, Li B, Oshima J, Ellis NA, Campisi J. Characterization of the human and mouse WRN $3^{\prime}->5^{\prime}$ exonuclease. Nucleic Acids Res. 2000;28:2396-2405.

75. Kamath-Loeb AS, Shen J-C, Schmitt MW, Loeb LA. The Werner syndrome exonuclease facilitates DNA degradation and high fidelity DNA polymerization by human DNA polymerase $\delta$. J Biol Chem. 2012;287:12480-12490.

76. von Kobbe C, Karmakar P, Dawut L, et al. Colocalization, physical, and functional interaction between Werner and Bloom syndrome proteins. J Biol Chem. 2002;277:22035-22044.

77. Singh DK, Popuri V, Kulikowicz T, et al. The human RecQ helicases BLM and RECQL4 cooperate to preserve genome stability. Nucleic Acids Res. 2012;40:6632-6648.

78. Popuri V, Huang J, Ramamoorthy M, Tadokoro T, Croteau DL, Bohr VA. RECQL5 plays co-operative and complementary roles with WRN syndrome helicase. Nucleic Acids Res. 2013;41:881-899.

79. Aparicio T, Baer R, Gautier J. DNA double-strand break repair pathway choice and cancer. DNA Repair. 2014;19:169-175.

80. Kakarougkas A, Jeggo PA. DNA DSB repair pathway choice: an orchestrated handover mechanism. Br J Radiol. 2014;87:20130685.

81. Nimonkar AV, Genschel J, Kinoshita E, et al. BLM-DNA2-RPAMRN and EXO1-BLM-RPA-MRN constitute two DNA end resection machineries for human DNA break repair. Genes Dev. 2011;25: $350-362$.

82. Sturzenegger A, Burdova K, Kanagaraj R, et al. DNA2 cooperates with the WRN and BLM RecQ helicases to mediate long-range DNA-end resection in human cells. J Biol Chem. 2014;289:27314-27326.

83. Bothmer A, Rommel PC, Gazumyan A, et al. Mechanism of DNA resection during intrachromosomal recombination and immunoglobulin class switching. J Exp Med. 2013;210:115-123.

84. Costelloe T, Louge R, Tomimatsu N, et al. The yeast Fun 30 and human SMARCAD1 chromatin remodellers promote DNA end resection. Nature. 2012;489:581-584.

85. Aymard F, Bugler B, Schmidt CK, et al. Transcriptionally active chromatin recruits homologous recombination at DNA double-strand breaks. Nat Struct Mol Biol. 2014;21:366-374.

86. Pai CC, Deegan RS, Subramanian L, et al. A histone H3K36 chromatin switch coordinates DNA double-strand break repair pathway choice. Nat Commun. 2014;5:4091.

87. Grabarz A, Guirouilh-Barbat J, Barascu A, et al. A role for BLM in double-strand break repair pathway choice: prevention of CtIP/Mre11mediated alternative nonhomologous end-joining. Cell Rep. 2013;5: 21-28.

88. Keijzers G, Maynard S, Shamanna RA, Rasmussen LJ, Croteau DL, Bohr VA. The role of RecQ helicases in non-homologous end-joining. Crit Rev Biochem Mol Biol. Epub 2014 July 22.

89. Shamanna RA, Singh DK, Lu H, et al. RECQ helicase RECQL4 participates in non-homologous end joining and interacts with the $\mathrm{Ku}$ complex. Carcinogenesis. 2014;35:2415-2424.

90. Singh DK, Karmakar P, Aamann M, et al. The involvement of human RECQL4 in DNA double-strand break repair. Aging Cell. 2010;9: 358-371.

91. Swuec P, Costa A. Molecular mechanism of double Holliday junction dissolution. Cell Biosci. 2014;4:36.

92. Bizard AH, Hickson ID. The dissolution of double Holliday junctions. Cold Spring Harb Perspect Biol. 2014;6:a016477. 
93. Manthei KA, Keck JL. The BLM dissolvasome in DNA replication and repair. Cell Mol Life Sci. 2013;70:4067-4084.

94. Prince PR, Emond MJ, Monnat RJ Jr. Loss of Werner syndrome protein function promotes aberrant mitotic recombination. Genes Dev. 2001;15:933-938.

95. Islam MN, Paquet N, Fox D 3rd, et al. A variant of the breast cancer type 2 susceptibility protein (BRC) repeat is essential for the RECQL5 helicase to interact with RAD51 recombinase for genome stabilization. J Biol Chem. 2012;287:23808-23818.

96. Paliwal S, Kanagaraj R, Sturzenegger A, Burdova K, Janscak P. Human RECQ5 helicase promotes repair of DNA double-strand breaks by synthesis-dependent strand annealing. Nucleic Acids Res. 2014;42: 2380-2390.

97. Rouzeau S, Cordelières FP, Buhagiar-Labarchède G, et al. Bloom's syndrome and PICH helicases cooperate with topoisomerase II alpha in centromere disjunction before anaphase. PLoS One. 2012;7:e33905.

98. Barefield C, Karlseder J. The BLM helicase contributes to telomere maintenance through processing of late-replicating intermediate structures. Nucleic Acids Res. 2012;40:7358-7367.

99. Russell B, Bhattacharyya S, Keirsey J, et al. Chromosome breakage is regulated by the interaction of the BLM helicase and topoisomerase IIalpha. Cancer Res. 2011;71:561-571.

100. Ramamoorthy M, Tadokoro T, Rybanska I, et al. RECQL5 cooperates with Topoisomerase II alpha in DNA decatenation and cell cycle progression. Nucleic Acids Res. 2012;40:1621-1635.

101. Sharma S, Phatak P, Stortchevoi A, Jasin M, Larocque JR. RECQ1 plays a distinct role in cellular response to oxidative DNA damage. DNA Repair. 2012;11:537-549.

102. Tadokoro T, Ramamoorthy M, Popuri V, et al. Human RECQL5 participates in the removal of endogenous DNA damage. Mol Biol Cell. 2012;23:4273-4285.

103. Lu X, Parvathaneni S, Hara T, Lal A, Sharma S. Replication stress induces specific enrichment of RECQ1 at common fragile sites FRA3B and FRA16D. Mol Cancer. 2013;12:29.

104. Ohlenschläger O, Kuhnert A, Schneider A, et al. The N-terminus of the human RecQL4 helicase is a homeodomain-like DNA interaction motif. Nucleic Acids Res. 2012;40(17):8309-8324.

105. Xu X, Rochette PJ, Feyissa EA, Su TV, Liu Y. MCM10 mediates RECQ4 association with MCM2-7 helicase complex during DNA replication. EMBO J. 2009;28:3005-3014.

106. Liu Y. Rothmund-Thomson syndrome helicase, RECQL4: on the crossroad between DNA replication and repair. DNA Repair. 2010;9: 325-330.

107. Lu H, Fang EF, Sykora P, et al. Senescence induced by RECQL4 dysfunction contributes to Rothmund-Thomson syndrome features in mice. Cell Death Dis. 2014;5:e1226.

108. Smeets MF, DeLuca E, Wall M, et al. The Rothmund-Thomson syndrome helicase RECQL4 is essential for hematopoiesis. $J$ Clin Invest. 2014;124:3551-3565.

109. Rao VA, Conti C, Guirouilh-Barbat J, et al. Endogenous gammaH2AX-ATM-Chk2 checkpoint activation in Bloom's syndrome helicase-deficient cells is related to DNA replication arrested forks. Mol Cancer Res. 2007;5(7):713-724.

110. Sidorova JM, Kehrli K, Mao F, Monnat R Jr. Distinct functions of human RECQ helicases WRN and BLM in replication fork recovery and progression after hydroxyurea-induced stalling. DNA Repair. 2013;12:128-139.

111. Sidorova JM, Li N, Folch A, Monnat RJ Jr. The RecQ helicase WRN is required for normal replication fork progression after DNA damage or replication fork arrest. Cell Cycle. 2008;7:796-807.

112. Berti M, Ray Chaudhuri A, Thangavel S, et al. Human RECQ1 promotes restart of replication forks reversed by DNA topoisomerase I inhibition. Nat Struct Mol Biol. 2013;20:347-354.

113. Duxin JP, Moore HR, Sidorova J, et al. Okazaki fragment processingindependent role for human Dna2 enzyme during DNA replication. J Biol Chem. 2012;287:21980-21991.
114. Chabosseau P, Buhagiar-Labarchède G, Onclercq-Delic R, et al. Pyrimidine pool imbalance induced by BLM helicase deficiency contributes to genetic instability in Bloom syndrome. Nat Commun. 2011;2:368.

115. Naim V, Wilhelm T, Debatisse M, Rosselli F. ERCC1 and MUS81EME1 promote sister chromatid separation by processing late replication intermediates at common fragile sites during mitosis. Nat Cell Biol. 2013;15:1008-1015.

116. Ying S, Minocherhomji S, Chan KL, et al. MUS81 promotes common fragile site expression. Nat Cell Biol. 2013;15:1001-1007.

117. Franchitto A. Genome instability at common fragile sites: searching for the cause of their instability. Biomed Res Int. 2013;2013:730714.

118. Pirzio LM, Pichierri P, Bignami M, Franchitto A. Werner syndrome helicase activity is essential in maintaining fragile site stability. $J$ Cell Biol. 2008;180:305-314.

119. Chan KL, Palmai-Pallag T, Ying S, Hickson ID. Replication stress induces sister-chromatid bridging at fragile site loci in mitosis. Nat Cell Biol. 2009;11:753-760.

120. Sfeir A, Kosiyatrakul ST, Hockemeyer D, et al. Mammalian telomeres resemble fragile sites and require TRF1 for efficient replication. Cell. 2009;138:90-103.

121. Rizzo A, Salvati E, Porru M, et al. Stabilization of quadruplex DNA perturbs telomere replication leading to the activation of an ATRdependent ATM signaling pathway. Nucleic Acids Res. 2009;37: 5353-5364.

122. Popuri V, Hsu J, Khadka P, et al. Human RECQL1 participates in telomere maintenance. Nucleic Acids Res. 2014;42:5671-5688.

123. Ghosh AK, Rossi ML, Singh DK, et al. RECQL4, the protein mutated in Rothmund-Thomson syndrome, functions in telomere maintenance. J Biol Chem. 2012;287:196-209.

124. Opresko PL. Telomere ResQue and preservation - roles for the Werner syndrome protein and other RecQ helicases. Mech Ageing Dev. 2008;129:79-90.

125. Crabbe L, Verdun RE, Haggblom CI, Karlseder J. Defective telomere lagging strand synthesis in cells lacking WRN helicase activity. Science. 2004;306:1951-1953.

126. Arnoult N, Saintome C, Ourliac-Garnier I, Riou J-F, Londoño-Vallejo A. Human POT1 is required for efficient telomere C-rich strand replication in the absence of WRN. Genes Dev. 2009;23:2915-2924.

127. Bhattacharyya S, Keirsey J, Russell B, et al. Telomerase-associated protein 1, HSP90, and topoisomerase II $\alpha$ associate directly with the BLM helicase in immortalized cells using ALT and modulate its helicase activity using telomeric DNA substrates. J Biol Chem. 2009;284:14966-14977.

128. Mendez-Bermudez A, Hidalgo-Bravo A, Cotton VE, Gravani A, Jeyapalan JN, Royle NJ. The roles of WRN and BLM RecQ helicases in the alternative lengthening of telomeres. Nucleic Acids Res. 2012;40:10809-10820.

129. Edwards DN, Orren DK, Machwe A. Strand exchange of telomeric DNA catalyzed by the Werner syndrome protein (WRN) is specifically stimulated by TRF2. Nucleic Acids Res. 2014;42(12):7748-7761.

130. Zeman MK, Cimprich KA. Causes and consequences of replication stress. Nat Cell Biol. 2014;16(1):2-9.

131. Magdalou I, Lopez BS, Pasero P, Lambert SAE. The causes of replication stress and their consequences on genome stability and cell fate. Semin Cell Dev Biol. 2014;30:154-164.

132. Franchitto A, Pirzio LM, Prosperi E, Sapora O, Bignami M, Pichierri P. Replication fork stalling in WRN-deficient cells is overcome by prompt activation of a MUS81-dependent pathway. J Cell Biol. 2008; 183:241-252.

133. Sidorova JM. Roles of the Werner syndrome RecQ helicase in DNA replication. DNA Repair. 2008;7:1776-1786.

134. Ammazzalorso F, Pirzio LM, Bignami M, Franchitto A, Pichierri P. ATR and ATM differently regulate WRN to prevent DSBs at stalled replication forks and promote replication fork recovery. $E M B O J$. 2010;29:3156-3169. 
135. Murfuni I, De Santis A, Federico M, Bignami M, Pichierri P, Franchitto A. Perturbed replication induced genome wide or at common fragile sites is differently managed in the absence of WRN. Carcinogenesis. 2012;33:1655-1663.

136. Davies SL, North PS, Hickson ID. Role for BLM in replicationfork restart and suppression of origin firing after replicative stress. Nat Struct Mol Biol. 2007;14:677-679.

137. Dietschy T, Shevelev I, Pena-Diaz J, et al. p300-mediated acetylation of the Rothmund-Thomson-syndrome gene product RECQL4 regulates its subcellular localization. J Cell Sci. 2009;122:1258-1267.

138. Chi Z, Nie L, Peng Z, et al. RecQL4 cytoplasmic localization: implications in mitochondrial DNA oxidative damage repair. Int $J$ Biochem Cell Biol. 2012;44:1942-1951.

139. De S, Kumari J, Mudgal R, et al. RECQL4 is essential for the transport of p53 to mitochondria in normal human cells in the absence of exogenous stress. J Cell Sci. 2012;125:2509-2522.

140. Gupta S, De S, Srivastava V, et al. RECQL4 and p53 potentiate the activity of polymerase $\gamma$ and maintain the integrity of the human mitochondrial genome. Carcinogenesis. 2014;35:34-45.

141. Croteau DL, Rossi ML, Canugovi C, et al. RECQL4 localizes to mitochondria and preserves mitochondrial DNA integrity. Aging Cell. 2012;11:456-466

142. Johnson JE, Cao K, Ryvkin P, Wang LS, Johnson FB. Altered gene expression in the Werner and Bloom syndromes is associated with sequences having G-quadruplex forming potential. Nucleic Acids Res. 2010;38:1114-1122.

143. Li XL, Lu X, Parvathaneni S, et al. Identification of RECQ1-regulated transcriptome uncovers a role of RECQ1 in regulation of cancer cell migration and invasion. Cell Cycle. 2014;13:2431-2445.

144. Sarkies P, Reams C, Simpson LJ, Sale JE. Epigenetic instability due to defective replication of structured DNA. Mol Cell. 2010;40: 703-713.

145. Sarkies P, Murat P, Phillips LG, Patel KJ, Balasubramanian S, Sale JE. FANCJ coordinates two pathways that maintain epigenetic stability at G-quadruplex DNA. Nucleic Acids Res. 2012;40: 1485-1498.

146. Pichierri P, Nicolai S, Cignolo L, Bignami M, Franchitto A. The RAD9-RAD1-HUS1 (9.1.1) complex interacts with WRN and is crucial to regulate its response to replication fork stalling. Oncogene. 2012;31:2809-2823.

147. Böhm S, Bernstein KA. The role of post-translational modifications in fine-tuning BLM helicase function during DNA repair. DNA Repair. 2014;22:z123-z132.

148. Eladad S, Ye TZ, Hu P, et al. Intra-nuclear trafficking of the BLM helicase to DNA damage-induced foci is regulated by SUMO modification. Hum Mol Genet. 2005;14(10):1351-1365.

149. Ouyang KJ, Woo LL, Zhu J, Huo D, Matunis MJ, Ellis NA. SUMO modification regulates BLM and RAD51 interaction at damaged replication forks. PLoS Biol. 2009;7(12):e1000252.

150. Ouyang KJ, Yagle MK, Matunis MJ, Ellis NA. BLM SUMOylation regulates ssDNA accumulation at stalled replication forks. Front Genet. 2013;4:167.

151. Tikoo S, Madhavan V, Hussain M, et al. Ubiquitin-dependent recruitment of the Bloom Syndrome helicase upon replication stress is required to suppress homologous recombination. EMBO J. 2013;32: 1778-1792.

152. Curtin N. PARP inhibitors for anticancer therapy. Biochem Soc Trans. 2014;42:82-88.

153. Li B, Navarro S, Kasahara N, Comai L. Identification and biochemical characterization of a Werner's syndrome protein complex with Ku70/80 and poly(ADP-ribose) polymerase-1. J Biol Chem. 2004;279: 13659-13667.

154. Popp O, Veith S, Fahrer J, Bohr VA, Bürkle A, Mangerich A. Sitespecific noncovalent interaction of the biopolymer poly(ADP-ribose) with the Werner syndrome protein regulates protein functions. ACS Chem Biol. 2012;8:179-188.
155. von Kobbe C, Harrigan JA, May A, et al. Central role for the Werner syndrome protein/poly(ADP-Ribose) polymerase 1 complex in the poly(ADP-ribosyl)ation pathway after DNA damage. Mol Cell Biol. 2003;23:8601-8613.

156. Lebel M, Lavoie J, Gaudreault I, Bronsard M, Drouin R. Genetic cooperation between the Werner syndrome protein and poly(ADP-ribose) polymerase-1 in preventing chromatid breaks, complex chromosomal rearrangements, and cancer in mice. Am J Pathol. 2003;162:1559-1569.

157. von Kobbe C, Harrigan JA, Schreiber V, et al. Poly(ADP-ribose) polymerase 1 regulates both the exonuclease and helicase activities of the Werner syndrome protein. Nucleic Acids Res. 2004;32:4003-4014.

158. Blander G, Zalle N, Daniely Y, Taplick J, Gray MD, Oren M. DNA damage-induced translocation of the Werner helicase is regulated by acetylation. J Biol Chem. 2002;277:50934-50940.

159. Muftuoglu M, Kusumoto R, Speina E, Beck G, Cheng W-H, Bohr VA. Acetylation regulates WRN catalytic activities and affects base excision DNA repair. PLoS One. 2008;3:e1918.

160. Martin GM, Sprague CA, Epstein CJ. Replicative life-span of cultivated human cells. Effects of donor's age, tissue, and genotype. $L a b$ Invest. 1970;23:86-92.

161. Dhillon KK, Sidorova J, Saintigny Y, et al. Functional role of the Werner syndrome RecQ helicase in human fibroblasts. Aging Cell. 2007;6:53-61.

162. Warren ST, Schultz RA, Chang CC, Wade MH, Trosko JE. Elevated spontaneous mutation rate in Bloom syndrome fibroblasts. Proc Natl Acad Sci U S A. 1981;78:3133-3137.

163. Mao FJ, Sidorova JM, Lauper JM, Emond MJ, Monnat RJ. The human WRN and BLM RecQ helicases differentially regulate cell proliferation and survival after chemotherapeutic DNA damage. Cancer Res. 2010;70:6548-6555.

164. Keller C, Keller KR, Shew SB, Plon SE. Growth deficiency and malnutrition in Bloom syndrome. J Pediatr. 1999;134:472-479.

165. d'Adda di Fagagna F. Living on a break: cellular senescence as a DNA-damage response. Nat Rev Cancer. 2008;8:512-522.

166. Coppé J-P, Desprez P-Y, Krtolica A, Campisi J. The senescenceassociated secretory phenotype: the dark side of tumor suppression. Annu Rev Pathol Mech Dis. 2010;5:99-118.

167. Jeyapalan JC, Ferreira M, Sedivy JM, Herbig U. Accumulation of senescent cells in mitotic tissue of aging primates. Mech Ageing Dev. 2007; 128:36-44.

168. Waaijer ME, Parish WE, Strongitharm BH, et al. The number of p16INK4a positive cells in human skin reflects biological age. Aging Cell. 2012;11:722-725.

169. Collado M, Serrano M. Senescence in tumours: evidence from mice and humans. Nat Rev Cancer. 2010;10:51-57.

170. Moser MJ, Bigbee WL, Grant SG, et al. Genetic instability and hematologic disease risk in Werner syndrome patients and heterozygotes. Cancer Res. 2000;60:2492-2496.

171. Ogburn CE, Oshima J, Poot M, et al. An apoptosis-inducing genotoxin differentiates heterozygotic carriers for Werner helicase mutations from wild-type and homozygous mutants. Hum Genet. 1997;101:121-125.

172. Okada M, Goto M, Furuichi Y, Sugimoto M. Differential effects of cytotoxic drugs on mortal and immortalized B-lymphoblastoid cell lines from normal and Werner's syndrome patients. Biol Pharmacol Bull. 1998;21:235-239.

173. Lao VV, Welcsh P, Luo Y, et al. Altered RECQ helicase expression in sporadic primary colorectal cancers. Transl Oncol. 2013;6:458-469.

174. Agrelo R, Cheng WH, Setien F, et al. Epigenetic inactivation of the premature aging Werner syndrome gene in human cancer. Proc Natl Acad Sci US A. 2006;103:8822-8827.

175. Kawasaki T, Ohnishi M, Suemoto Y, et al. WRN promoter methylation possibly connects mucinous differentiation, microsatellite instability and $\mathrm{CpG}$ island methylator phenotype in colorectal cancer. Mod Pathol. 2007;21:150-158. 
176. Lee H, Flaherty P, Ji H. Systematic genomic identification of colorectal cancer genes delineating advanced from early clinical stage and metastasis. BMC Med Genomics. 2013;6:54.

177. Aggarwal M, Sommers JA, Shoemaker RH, Brosh RM. Inhibition of helicase activity by a small molecule impairs Werner syndrome helicase (WRN) function in the cellular response to DNA damage or replication stress. Proc Natl Acad Sci U S A. 2011;108:1525-1530.

178. Nguyen GH, Dexheimer TS, Rosenthal AS, et al. A small molecule inhibitor of the BLM helicase modulates chromosome stability in human cells. Chem Biol. 2013;20:55-62.
179. Helleday T, Petermann E, Lundin C, Hodgson B, Sharma RA. DNA repair pathways as targets for cancer therapy. Nat Rev Cancer. 2008;8:193-204.

180. Evers B, Helleday T, Jonkers J. Targeting homologous recombination repair defects in cancer. Trends Pharmacol Sci. 2010;31:372-380.

181. Ashworth A, Lord CJ, Reis-Filho JS. Genetic interactions in cancer progression and treatment. Cell. 2011;145(1):30-38.

182. Brough R, Frankum JR, Costa-Cabral S, Lord CJ, Ashworth A. Searching for synthetic lethality in cancer. Curr Opin Genet Dev. 2011;21:34-41.

\section{Publish your work in this journal}

Advances in Genomics and Genetics is an international, peer reviewed, open access journal that focuses on new developments in characterizing the human and animal genome and specific gene expressions in health and disease. Particular emphasis will be given to those studies that elucidate genes, biomarkers and targets in the development of new or improved therapeutic interventions. The journal is characterized by the rapid reporting of reviews, original research, methodologies, technologies and analytics in this subject area. The manuscript management system is completely online and includes a very quick and fair peer-review system. Visit http://www.dovepress.com/ testimonials.php to read real quotes from published authors.

Submit your manuscript here: http://www.dovepress.com/advances-in-genomics-and-gene-expression-journal 